\title{
Práticas alimentares cotidianas de mulheres obesas moradoras da Favela da Rocinha (Rio de Janeiro, RJ, Brasil)
}

\author{
Daily eating habits of obese women living in Rocinha Shanytown \\ (Rio de Janeiro, RJ, Brazil)
}

Vanessa Alves Ferreira ${ }^{1}$ Rosana Magalhães ${ }^{2}$
${ }^{1}$ Departamento de Nutrição, Universidade Federal do Vale do Jequitinhonha e Mucuri. Rua da Glória 187, Centro. 39100-000 Diamantina MG.

vanessa.nutr@ig.com.br

${ }^{2}$ Departamento de Ciências Sociais, Escola Nacional de Saúde Pública Sergio Arouca, Fundação Oswaldo Cruz.

\begin{abstract}
This article presents conclusions of research conducted at Ensp/Fiocruz, as part of a master's degree course. One of the objectives of the research to investigate the eating habits of women living in the Rocinha Shantytown (Rio de Janeiro, $R J$, Brazil) from a socio-anthropological perspective. The results revealed that the eating habits of the group were repetitive, with few variations in the menu consisting basically of rice, bean, sugars and fats. We further observed the rejection of industrialized and canned products. This food consumption pattern seems to conform to Brazilian food culture revealing the preservation of the national identity based on feeding habits. Consequent$l y$, it is necessary to set aside presuppositions regarding the relationship between food consumption and obesity, especially with respect to the predominant idea of changes in diet with the incorporation of a "modern" or "western" diet that prevail in studies in the field of nutrition in Brazil. In this sense, we signaled the need to reassert a multidimensional approach for studies about food and nutrition in the country. This proposal involves overcoming restricted conceptual outlooks and the creation of new avenues of investigation.
\end{abstract}

Key words Anthropology, Nutrition, Eating habits, Obesity
Resumo $O$ presente artigo apresenta conclusões de uma pesquisa desenvolvida na Ensp/Fiocruz, como parte do curso de mestrado. A pesquisa teve como um dos objetivos investigar as práticas alimentares de mulheres moradoras da Favela da Rocinha (Rio de Janeiro, RJ) na perspectiva socioantropológica. Os resultados revelaram que a alimentação do grupo era monótona, com poucas variações do cardápio composto basicamente por arroz, feijão, açúcares e gorduras. Observamos ainda a rejeição aos produtos industrializados $e$ enlatados. Este padrão de consumo alimentar parece se aproximar da cultura alimentar brasilei$r a$, revelando a preservação da identidade nacional a partir da alimentação. Dessa forma, há necessidade de superar pressupostos em torno da relação entre consumo alimentar e obesidade, especialmente no que diz respeito à ideia predominante de mudanças na dieta com a incorporação de uma dieta "moderna" ou "ocidental" que permeia grande parte dos estudos no campo da nutrição no Brasil. Nessa direção, sinalizamos a necessidade de resgatar a abordagem multidimensional para os estudos sobre alimentação e nutrição no país. Tal proposta implica a superação de quadros conceituais restritos e a construção de novas agendas de investigação.

Palavras-chave Antropologia, Nutrição, Práticas alimentares, Obesidade 


\section{Introdução}

As análises a respeito da dimensão cultural e ideológica presentes nas práticas alimentares se consolidam no Brasil a partir das décadas de 40 e 50 por intermédio dos exames etnográficos realizados pelo campo da antropologia. Os ditos "estudos de comunidade" dos anos 50 revelam-se como preciosas contribuições analíticas sobre a alimentação na perspectiva da cultura alimentar. Tais estudos buscaram apreender o universo dos valores, hábitos e padrões alimentares através da descrição dos meios de aquisição, composição e preparo dos alimentos; assim como dos tabus e crenças relacionados à alimentação. Alguns cientistas sociais empreenderam, ainda, estudos sobre alimentação e saúde, realizando inquéritos nutricionais junto à classe trabalhadora. Muitos desses trabalhos subsidiaram políticas públicas, sobretudo nas décadas de 40, 50 e 60, destacando-se os trabalhos de Josué de Castro.

Nos anos setenta surgem as análises antropológicas voltadas para as condições de vida das classes trabalhadoras, em que são focalizadas as diferentes situações de escassez a que se veem submetidos tais grupos. Essas investigações ampliaram o universo analítico de característica puramente descritiva e revelaram dados importantes sobre as práticas e padrões de consumo das classes trabalhadoras mediadas pela esfera da dependência econômica. Nessa direção, podemos destacar as investigações propostas por Antônio Cândido', Klaas Woortman² e Gilberto Velho ${ }^{3}$.

Nos anos 1980, os estudos da antropologia se debruçaram sobre as temáticas das representações sociais do corpo, da saúde e da doença das classes populares, especialmente em decorrência da maior aproximação entre as ciências sociais e as ciências da saúde. Nessa direção, podemos citar as investigações propostas por Loyo$\mathrm{la}^{4}$ e Duarte ${ }^{5}$. Mas recentemente, a partir da década de 1990, observa-se a concentração de estudos sobre o contexto da alimentação simbólica, os regionalismos culinários, comida e religião, os novos contornos da comensalidade urbana, o fast-food, dentre outros - com destaque para os estudos de Rial ${ }^{6}$, Garcia ${ }^{7}$ e Lifschitz ${ }^{8}$.

Notam-se ainda iniciativas de aproximação e diálogo entre o campo das ciências sociais e a área da nutrição. Assim, algumas investigações empreenderam ricas contribuições para o estudo da alimentação, do corpo, da obesidade, da desnutrição, da prática de atividade física e estilo de vida dentro da perspectiva multidimensional, resgatando a dimensão socioeconômica e cultu- ral dos estudos sobre nutrição no país. Os trabalhos de Silva ${ }^{9}$ com as mulheres obesas e de baixa renda em Manguinhos (Rio de Janeiro, RJ); de Rotemberg ${ }^{10}$ com crianças desnutridas na Gávea (Rio de Janeiro, RJ); Tonial ${ }^{11}$ com as mulheres do Maranhão; Ferreira ${ }^{12}$ com as mulheres pobres e obesas da favela da Rocinha (Rio de Janeiro, RJ) e de Mendonça ${ }^{13}$ acerca das práticas alimentares e de atividade física em mulheres residentes em Niterói (RJ) trouxeram novas perspectivas para os estudos sobre alimentação e nutrição no país. A respeito dos estudos antropológicos sobre a alimentação no Brasil, sugerimos a leitura dos trabalhos de revisão propostos por Ana Maria Canesqui ${ }^{14,15}$.

Este estudo objetivou investigar as práticas alimentares de um grupo de mulheres moradoras da Favela da Rocinha, no Rio de Janeiro, na perspectiva socioantropológica. Este trabalho faz parte das conclusões de uma pesquisa realizada no curso de mestrado da Escola Nacional de Saúde Pública Sergio Arouca, da Fundação Oswaldo Cruz (Ensp/Fiocruz), a respeito da relação entre obesidade e pobreza. Ante a riqueza do material levantado, este artigo discute alguns aspectos desta investigação $0^{12}$. O trabalho apoia-se no entendimento de que a alimentação como uma prática imprescindível à sobrevivência humana, não se desvincula da totalidade da vida cotidiana dos indivíduos, mas é integrante das suas condições de vida. Dessa forma, para a sua apreensão torna-se necessário compreender o conjunto de circunstâncias de vida que envolvem o trabalho, os rendimentos, a família, a saúde, o lazer, entre outras situações cotidianas.

\section{Metodologia}

O estudo realizou-se em uma unidade básica de saúde do município do Rio de Janeiro, localizada na zona sul metropolitana da cidade. Neste trabalho, optou-se pelo emprego da metodologia qualitativa, em que foi priorizado o universo de hábitos, crenças, costumes e atitudes dos sujeitos. A pesquisa social parte do pressuposto de que "a consciência é mais condicionada pela inconsciência do que o contrário" ${ }^{16}$. São assim incorporadas dimensões mais profundas de análise, ou seja, as mediações interiorizadas pelos sujeitos ${ }^{17}$. Foram entrevistadas mulheres atendidas no ambulatório de nutrição da unidade e ainda moradoras da Favela da Rocinha. O trabalho de campo foi realizado em encontros semanais, totalizando 12 entrevistas. $\mathrm{O}$ instrumento de coleta 
de dados consistiu de um roteiro de entrevistas previamente validado contendo informações sobre a alimentação e as condições de vida do grupo. Nesta etapa optamos pela técnica da entrevista semiestruturada, que parte de certos questionamentos básicos apoiados em teorias e hipóteses, que interessam à pesquisa e que, em seguida, oferecem amplo campo de interrogativas, fruto de novas hipóteses que vão surgindo à medida que se recebem as respostas dos informantes ${ }^{18}$. Na etapa de análise dos resultados, optou-se pela técnica de análise dos conteúdos, como propõem Trivi$\operatorname{nos}^{18}$ e Bardin ${ }^{19}$. Neste tipo de técnica, podemos encontrar respostas para as questões formuladas e também podemos confirmar ou não as afirmações estabelecidas antes do trabalho de investigação. Além disso, esta técnica permite a "descoberta do que está por trás dos conteúdos manifestos", conforme afirma Minayo ${ }^{17}$. As entrevistas foram transcritas na íntegra, e realizamos uma leitura minuciosa de todo o material disponível, sublinhando as ideias principais ligadas à fundamentação teórica.

\section{O contexto de vida, o trabalho e o lazer das mulheres da Rocinha}

As mulheres investigadas apresentaram média de idade de 48 anos. A maior parte era proveniente da Região Nordeste do país. Todas as entrevistadas eram moradoras da Favela da Rocinha. A vida na favela revelou um cotidiano difícil, marcado pela dupla jornada de trabalho, que incluía os afazeres domésticos, os cuidados com os filhos, as ocupações do trabalho, a rotina de subir e descer as ladeiras da favela, as tensões desencadeadas pela falta do dinheiro, pelo convívio com a criminalidade e a violência. Esta realidade foi expressa frequentemente através de declarações do tipo: "é muita luta"; "à noite estou morta, exausta”.

As mulheres entrevistadas eram em sua maioria pretas ou pardas, apresentaram baixo nível educacional (menos de três anos de estudo) e se encontravam inseridas em postos de trabalho de menor prestígio exercendo atividades de diarista, doméstica, costureira, manicure, artesã, entre outras. A precarização do mercado de trabalho impunha ainda o trabalho sem vínculos trabalhistas, em que as mulheres exerciam suas atividades sem carteira assinada. A desqualificação das ocupações exercidas por essas mulheres se refletia nos baixos rendimentos: a média salarial observada foi de um a dois salários mínimos mensais. A maior parte das informantes foi considerada chefe do domicílio.

No que se refere às condições do domicílio e ao acesso ao equipamento de infraestrutura urbano, verificamos situações insatisfatórias de acesso a serviços de atenção à saúde, saneamento básico e limpeza pública: "volta e meia falta água"; "os lixeiros não vão pegar o lixo lá”. As condições de moradias se revelaram precárias, e a maior parte das habitações era de difícil acesso: "tem que subir a escadaria porque a kombi não sobe lá"; "[a minha casa] fica um pouco no alto". Os domicílios eram construídos com materiais do tipo telhas e tijolos, alguns ainda inacabados e em construção: "eu não terminei a minha casa, ainda não tem chão". Em geral, os domicílios eram compostos por quatro cômodos: sala, quarto, cozinha e banheiro de dimensões pequenas, que receberam denominações do tipo "apertadinho", "pequenininha", onde os cômodos encontram-se "tudo pertinho um do outro".

Nos relatos das mulheres da Rocinha, raramente foram citados momentos de descanso e lazer. O hábito de assistir televisão não se fazia presente na rotina diária dessas mulheres: "Não dá tempo nem de ver televisão. Com três filhos, se eu parar pra ver televisão as coisas acumulam"; "Eu quase não vejo televisão, só mesmo quando eu vou deitar". As atividades físicas de lazer demonstraram ser raras. Somente duas entrevistadas tinham o hábito de fazer "caminhadas": "Eu gosto de acordar e levantar cedo, cinco e meia pra mim é a hora. Eu levanto e vou caminhar. Aí nos dias que eu estou em casa eu vou fazer o serviço de casa; aí eu passo, lavo, cozinho, arrumo, faço tudo."

\section{A alimentação cotidiana das mulheres da Rocinha}

A rotina de alimentação das mulheres da Rocinha foi analisada na perspectiva qualitativa, objetivando colher informações acerca dos hábitos, costumes e critérios objetivos e subjetivos para a seleção dos alimentos. Nesse sentido, verificamos que a aquisição, a seleção e o preparo dos alimentos eram atividades realizadas pelas próprias mulheres. As representações sociais sobre os papéis de homens e mulheres na sociedade conferem as mulheres a sua atuação no "mundo doméstico", enquanto os homens atuam no "mundo público". Dessa forma, o universo da casa e os cuidados com os filhos são papéis da mãe e da donade-casa, ou seja, tarefas predominantemente fe- 
mininas. Nessa direção, as mulheres foram consideradas as principais responsáveis pelo gerenciamento da alimentação da família ${ }^{20,21}$.

A compra dos alimentos é feita em hipermercados localizados em bairros adjacentes à Rocinha ou na própria favela: "eu compro nas Sendas de São Conrado"; "eu compro lá mesmo na Rocinha"; "às vezes no supermercado, às vezes no sacolão na Rocinha". O pagamento da alimentação adquirida era realizado à vista, sempre em dinheiro, revelando a exclusão do grupo à dinâmica do mercado de crédito: "eu só compro (alimentação) em dinheiro".

$\mathrm{O}$ regime alimentar das mulheres pobres e obesas da Rocinha era monótono, com poucas variações do cardápio e composto basicamente por três refeições diárias: café da manhã, almoço e jantar. O lanche da tarde não representa uma prática alimentar no grupo: "a tarde, é raro eu lanchar"; "de tarde não como nada, é muito difícil eu comer alguma coisa”. Entretanto, a centralidade do regime recai sobre a refeição do almoço. As demais refeições nem sempre são habituais. O café da manhã muitas vezes não é realizado pelas mulheres ou se resume ao consumo somente da infusão do café preto: "de manhã eu não tomo café, não como nada"; "de manhã mesmo é só um pinguinho de café". Das mulheres que revelaram realizar o café da manhã, este inclui "café com leite"; "pão e manteiga". Aqui, a tradição nordestina do consumo de itens como o milho, a pamonha e o beiju não é mantida, como revelaram as próprias mulheres entrevistadas ao falarem sobre o consumo de alimentos em sua terra natal: "nosso café da manhã era inhame, batata, abóbora, bananas, beiju"; "o café da manhã lá em casa era milho, papa de milho, pamonha".

O almoço compreende o trinômio "arroz, feijão e carne", sendo a carne impreterivelmente o frango. O frango assume lugar de destaque no grupo, especialmente o frango assado. Não constatamos o consumo de peixe e carne bovina pelas entrevistadas. Frequentemente revelaram adicionar a "farinha" e o "macarrão" à alimentação do almoço. $\mathrm{O}$ consumo de legumes poucas vezes foi citado pelas entrevistadas, com exceção da "batata" e da "abóbora". Também não foi verificado o consumo de verduras e frutas na rotina alimentar das mulheres. Os alimentos do almoço, diferentemente do café da manhã, parecem revelar maior aproximação com a cultura alimentar nordestina na predileção por itens como os grãos, os tubérculos e os farináceos, tal como as mulheres se referiram quando falaram de sua alimentação na terra natal.
Verificamos uma dinâmica complexa operando na refeição do jantar pelo grupo. Algumas mulheres disseram consumir no jantar a mesma alimentação praticada no almoço; outras revelaram maior variedade no consumo de alimentos nesta refeição, citando o "cafezinho com leite"; "sopinha de verdura"; "biscoitinho"; "churrasquinho". Por não fazerem uso da "comida", esta refeição é tida como isenta pelo grupo: "coisa mais difícil é eu jantar"; "nem janto, é muito difícil eu comer à noite". Mudanças na conformação do jantar têm sido observadas em estudos sobre as práticas alimentares no Brasil. O jantar compartilhado entre os integrantes da família revela-se como um acontecimento raro ${ }^{22}$. A substituição do jantar "tradicional" por lanches também tem sido uma prática frequente nas famílias brasileiras e revela as novas dinâmicas da alimentação contemporâneas: horários distintos para a realização das refeições de pais e filhos, a praticidade, o hábito de realizar as refeições em frente à televisão e em cômodos separados, dentre outras situações.

A alimentação consumida pelas mulheres é a "bem temperada", com "tempero gostoso", "natural". Em oposição, os temperos industrializados não são bem-vindos no cardápio das mulheres: "gosto mesmo é de tempero natural"; "caldo knor, essas coisas, eu não uso"; "não gosto muito de Arisco". Entre os temperos utilizados no cardápio estavam o "sal"; o "alho"; a "cebola"; a "pimenta-do-reino" e o "colorau". Esta certa resistência aos itens processados parece ter relação com a trajetória de vida cultural das mulheres, no plantio e cultivo do roçado de subsistência: "Minha mãe tinha um botijão grande que ela guardava feijão, arroz, farinha, meu pai fazia, a gente. Tudo assim natural, tudo fresco. Não tinha nada assim industrializado, era tudo plantio, tudo fresco"; "Não tinha remédio, não tinha essas coisas, não. Arroz a gente comia aquilo tudo durante o ano; café era torrado na hora, pisado no pilão."

Informações sobre preferências no consumo de alimentos revelaram o lugar privilegiado para os doces como o "doce de banana"; "bolo de milho"; "sorvete"; "goiabada". O uso do açúcar no cotidiano do grupo mostrou-se frequente, normalmente combinado ao café. Embora houvesse um certo constrangimento em revelar o consumo do açúcar no lar: "quase não como"; "como, mas só de manhã no café"; "é muito pouco". Esse comportamento também foi verificado nos relatos acerca do consumo de frituras, muitas vezes através de frases ambíguas: "eu não devo, mas como"; "eu como fritura, não deveria, mas como, 
sim". No entanto, o gosto pelas preparações fritas foi frequente entre as mulheres. A "batata frita", a "polenta", o "frango frito" e a "carne de porco frita" foram os alimentos mais consumidos. Tais relatos revelaram o conhecimento acerca das relações entre a ingestão de açúcares e gorduras e a frequência da obesidade. Outros itens apontados como os alimentos preferidos foram as carnes mais ricas em gordura, como a "carne de porco", a "feijoada" e a "carne seca" e importantes fontes de carboidratos, tais como a "macarronada", a "farofa" e a "polenta".

Variações no cardápio de fim de semana raramente foram citadas pelo grupo: "não muda"; "não tem nada de muito diferente"; "é a mesma que eu faço durante a semana". A este respeito, Canesqui ${ }^{23}$ verificou em seu trabalho variações na alimentação das famílias pobres no almoço de fim de semana, especialmente nos almoços de domingo. Segundo a autora, nessas ocasiões as famílias diversificavam o cardápio com o intuito de romper com o cotidiano. Entretanto, o agravamento das condições de vida em meio urbano parece ter comprometido as alterações na dieta do fim de semana das classes populares, tendência apontada por Alba Zaluarr ${ }^{24}$ em seu estudo com os pobres da Cidade de Deus (Rio de Janeiro, RJ). Entre as mulheres da Rocinha, esta tendência é reforçada: "Antigamente eu fazia, hoje em dia eu não faço"; "Quando tem eu faço alguma coisa diferente. Por exemplo, na semana é arroz, feijão e ovo, mas no domingo eu não quero aquilo [...] eu como se não tiver outra coisa, mas se tiver uma opção de escolha, claro que eu não vou comer isso."

Assim, notamos nos discursos que a variação do cardápio dos fins de semana era idealizada pelas mulheres. Essa mudança na alimentação cotidiana demonstrou ser uma aspiração, um desejo do grupo. Contudo, tais variações eram demasiadamente limitadas ante as condições materiais das mulheres.

No que compreende a realização de festas e celebrações, verificamos que eram raras no grupo. Das 12 entrevistadas, apenas uma informante disse realizar festas eventuais, que denominou de festa do tipo "americana", em que "cada um leva uma coisa". Nessas ocasiões, consomem os alimentos considerados prediletos, compreendendo os doces e as frituras em versões diferenciadas. A dieta nessas ocasiões muda, e dentre os alimentos mais citados pelas informantes apareceram: o bolo, os docinhos ("brigadeiro", "olho de sogra"), os refrigerantes e os salgadinhos ("coxinha", "empadinha", "pastel”).
As condições de pobreza entre as mulheres tende a forjar diferentes arranjos de sobrevivência no grupo. Nessa direção, observamos a fragilização das redes de solidariedade normalmente desenvolvidas pelas classes populares, que Canesqui ${ }^{23}$ denominou de "circuitos de dependência", compreendendo a prática do empréstimo de alimentos entre a vizinhança. As situações adversas de vida parecem extinguir pouco a pouco este comportamento no grupo: "eu já não peço pra não me pedirem emprestado"; "se eu pego emprestado, eu tenho que pagar. O que eu compro é pouco, se eu for pagar eu fico sem". Tal comportamento parece ser um recurso para economia no lar. Mas também envolve o pudor de expor aos demais à situação de escassez de alimentos que delimita a margem entre a pobreza e a miséria absoluta que a falta de alimentos representa: "nunca pedi um pó de café a ninguém porque eu fico com vergonha"; "pra mim chegar e pedir: fulano, me empresta isso? Ah, não eu não gosto!"; "eles não pedem, então procuro não pedir". Assim, o empréstimo, quando realizado, ocorre somente entre familiares, "os filhos primeiro"; "quando é minha cunhada, meus sobrinhos, aí eu dou".

A esse respeito, em estudo recente Canesqui ${ }^{22}$ verificou mudanças nas práticas alimentares das famílias trabalhadoras com a diminuição das práticas de solidariedade e de empréstimos de alimentos entre a vizinhança, afrouxando o sentido de coletividade. Para as informantes, isso se explica pelo esnobismo e individualismo dos novos moradores. A autora alerta que esse fato torna algumas famílias bastante vulneráveis à escassez alimentar, tal como, por exemplo, as famílias chefiadas por mulheres sós ou separadas.

Alimentos "proibidos" ou que não são deliberadamente incluídos na alimentação diária são raros. Na verdade, através de respostas como "não sei", "não tem porque a gente nunca tem", as mulheres entrevistadas revelaram dificuldade em citar alimentos cujo consumo era rejeitado: "Gosto de tudo, como de tudo"; "Eu como de tudo, não tem nada assim que eu não coma”.

Alimentos considerados de "luxo" pelo grupo são a "comida grã-fina, comida de rico", compreendendo itens como o "pernil", o "peru", o "bacalhau", o "queijo" e o "presunto". A alimentação idealizada pelo grupo inclui as "frutas", o "queijo", o "iogurte"; o "peixe" e a "carne vermelha", gêneros mais caros e cujo acesso é difícil: "As frutas estão muito caras e o dinheiro não dá pra comprar"; "Eu gostaria de comprar e às vezes eu não posso comprar é o queijo, o iogurte [...] porque é caro e não dá pra comprar"; "Frutas 
boas, pera, uva, essas coisas assim é muito caro, eu só compro mesmo em promoção [...] se não tiver promoção eu não compro, não".

A reduzida margem para a escolha da alimentação da família impõe o consumo de alimentos de digestão mais demorada que promovem maior saciedade. Dessa forma, o regime "básico", "principal” refere-se à combinação "feijão e arroz" que representa "a comida que a gente precisa", que "alimenta a gente", que "enche a barriga", através da qual "não se passa fome"; "Verdura é muito difícil, nem todo pobre compra aquele negócio de verdura [...] por isso que eu não faço dieta porque eu não posso, não posso comer legumes direito”.

$\mathrm{O}$ alimento para as mulheres pobres da Rocinha está associado à ideia de sobrevivência e manutenção da vida humana: "é tudo que a pessoa necessita pra viver"; "sem ele não se vive”. A comida, por sua vez, assume um sentido ambíguo. Pode estar relacionada à comida classificada como "normal", ao "básico", referindo-se ao "arroz, feijão e carne", ou somente ao "arroz e feijão". Mas também pode referir-se ao excesso, à "gulodice", ao supérfluo: "é comida porque a gente come, mas é uma coisa que a gente pode passar sem ela"; "comida dá impressão de gulodice"; "é tudo que for gostoso".

Nessa direção, para DaMatta ${ }^{25}$ os brasileiros sabem reconhecer que o alimento contém substâncias nutritivas, mas reconhecem também que nem todo "alimento" pode ser considerado "comida”. A transformação do alimento em comida envolve a forma como são escolhidos, preparados, misturados, cozidos, com quem são compartilhados e em que ocasiões são consumidos. Ou seja, a transformação dos alimentos em comida requer impregná-los de símbolos culturais.

No entanto, é a comida "normal" que compõe a refeição. Refeição para as mulheres é o "almoço", no qual aparece a comida que sustenta e satisfaz. Contrariamente, o lanche constitui-se como a "não refeição", porque nele não se faz uso da comida. O lanche é "uma coisa mais leve", sendo inclusive desprestigiado pelo grupo: "não ligo muito pro lanche”; “é uma bobagem não é comida”. Assim, eventualmente quando realizam o lanche, os itens consumidos revelam a desqualificação desta refeição, aparecendo sempre no diminutivo: "pãozinho" "copinho de leite", "biscoitinho". A sobremesa para o grupo é um "complemento" que não faz parte da rotina alimentar: "difícil de ter", "não estou acostumada a comer sobremesa".

Valores acerca dos alimentos processados incluindo os enlatados assumem para as mulhe- res da Rocinha conotação negativa, sendo caracterizados como prejudiciais à saúde. Considerados alimentos "não naturais" relacionam-se ao uso de conservantes e substâncias desconhecidas pelas mulheres que vivenciaram as experiências de plantar, colher e processar seus próprios alimentos no roçado de subsistência. A comida da roça "não tinha remédio", era "tudo natural, tudo fresco". Observamos aqui uma certa influência do discurso médico na prática alimentar das mulheres reforçado pelos aspectos culturais. Dessa maneira, os gêneros enlatados são rejeitados pelas mulheres: "enlatado [...] eu acho horrível [...] não gosto de nada enlatado porque eu acho que aquilo deve fazer mal”; "eu não gosto muito de enlatado, a comida fica ali naquela lata, né? Apesar de ter validade, de ter um controle, mas eu não gosto de enlatado"; "eu gosto de comida fresquinha, feita na hora. Eu fui criada assim, tudo fresquinho"; "enlatado não é boa alimentação"; "lá em casa não entra essas coisas de enlatado, não. São essas coisas que vêm em lata e eu não gosto, eu não sou de comer essas coisas. Eu acho que é porque eu fui criada na roça comendo aquelas coisas, então eu acho que a comida enlatada tem remédio".

Contrariamente, o alimento diet relaciona-se à saúde. É o alimento isento de açúcar e gordura, alimento "leve", utilizado "pra emagrecer". Por essa razão, é desejado pelo grupo: "eu gosto"; "deve ser bom"; "aqueles que não vão causar tanto mal à pessoa”. Embora as mulheres não tenham como adquirir: "só não dá pra comprar"; "é bem mais caro e eu nunca compro". Observamos novamente a penetração das informações de profissionais de saúde, assim como dos meios de comunicação entre o grupo: "[diet] eu acho que deve ser bom. Às vezes fala na televisão que não é bom e outros falam que é bom. Eu acho que é bom, mas eu acho que tem que ter o controle porque tudo em excesso acaba não fazendo bem, engorda sei, lá”; "eu acho que faz mal é aquele ovo que eles dizem que é diet mas não é, aquilo tem colesterol do mesmo jeito"; "[diet] é pra ajudar a manter a forma, não é isso?” A esse respeito, podemos destacar que esses "novos" produtos constituem elementos de distinção social, como bem afirmou Freitas ${ }^{26}$. Tais produtos, embora valorizados e desejados pelo grupo, demarcam a diferenciação social entre "pobres" e "ricos", pois são inacessíveis para as mulheres ante as limitações de ordem material a que estão submetidas em seu cotidiano de vida. Assim, embora os alimentos diet estejam associados à ideia de saúde e status social, seu consumo é in- 
O estudo com as mulheres moradoras da Rocinha revelou que a diferença na posição social entre ricos e pobres promovia também diferenciais na alimentação. Dessa forma, para as mulheres investigadas, a alimentação do rico significava a comida "boa", "cara", de "qualidade", diante da margem de escolha que os meios materiais propiciam ao grupo: "Eles comem de tudo! Eles podem comer o que querem"; "Eles compram o que há de mais caro, e a gente procura comprar o que é mais barato"; "Comida de pobre é uma comida pesada, de rico é mais leve. Comida de roça é comida pesada, com gordura de porco, muito pesada. Então o rico não come assim, não. $\mathrm{O}$ rico come as coisas melhores que o pobre, porque é rico. Coisa boa. E pobre não come essas coisas boas"; "Comida de rico é outra coisa! Tem o dia pra comer, de tudo tem um dia. Um dia de peixe, de carne, de frango. Cada dia tem uma comida diferente. O feijão é diferente, o feijão de rico tem tudo, de pobre só tem osso, comida de cachorro"; "Eles procuram comprar essas coisas importadas, o que é de melhor. Se eles podem comprar, tudo bem".

Para as mulheres da Rocinha, o regime do rico vincula-se também a outras concepções: comida "leve", "light", "para sempre manter a forma". Ainda na concepção das entrevistadas, o rico "come pouco", "uma coisinha de nada". Nestas expressões, nota-se uma inversão de valores entre o regime do rico e o regime do pobre. Para as mulheres, na dieta do rico impera a qualidade em detrimento da quantidade dos alimentos, enquanto na dieta do pobre a quantidade sobrepõe a qualidade dos itens: "pobre visa à quantidade e não à qualidade" - o que torna a alimentação do rico, neste aspecto, inferior à dieta consumida pelo pobre. O menor consumo de comida pelos ricos na concepção das mulheres está intimamente relacionado à fraqueza, a doença e até mesmo à morte: "Rico come uma coisinha à toa, coitado! Rico não sabe comer. Eu trabalhava pro seu Luiz e dizia: coitado do seu Luiz! Seu Luiz, o senhor precisa comer, o que que o senhor vai comer? De manhã eu falava: vai tomar café? Eu batia aquele negócio lá, a vitamina dele, ele tomava. Até logo, até logo. Já tomou café, seu Luiz? Ele dizia: já. Eu dizia: meu Deus do céu, esse

homem vai morrer! Rico come é pouquinha coisa. O dia em que ele foi comer o meu vatapá lá em casa, eu disse: você está preparado? Então come! [risos]"; "[rico] come pouco, tão tudo morrendo, depois tem que enterrar"; "Eu acho que pobre se alimenta mais melhor do que rico. Eu acho porque quando eu trabalhei em casa de família eu fazia comida pra eles, era uma coisinha de nada".

Em oposição, a comida do pobre, para as entrevistadas, é aquela em que não há qualquer possibilidade de escolha em face das condições econômicas do grupo. A pobreza é que justifica a alimentação que conseguem realizar: "pobre tem que comer o que o dinheiro dá"; "tem que comer o que tem". A alimentação do pobre é a "comida grosseira", "comida da roça", "pesada". Compreende basicamente o "arroz e o feijão"; verduras, legumes e frutas raramente aparecem no cardápio: "legumes eu [...] não ligo muito"; "às vezes eu como uma fruta, mas é raro"; "verdura é muito difícil". A exclusão desses gêneros na dieta das mulheres relaciona-se muitas vezes ao valor monetário dos itens. Dessa forma, revelam o desejo em adquirir esses alimentos: "a gente tem vontade de comer, mas não pode, o dinheiro não dá"; "a gente vê aquelas coisas e não pode comprar". A ausência desses gêneros no regime alimentar das mulheres entrevistadas relaciona-se à pobreza a que estão submetidas em seu cotidiano: "às vezes, quando tenho dinheiro pra comprar, eu compro uma goiaba, uma melancia, às vezes uma banana".

\section{Conclusão}

A análise das entrevistas permitiu reforçar nosso argumento inicial de que os estudos acerca da alimentação dos indivíduos e grupos sociais impõem uma abordagem multidimensional através da articulação das dimensões biológicas, socioeconômicas e culturais vivenciadas pelos indivíduos em seu cotidiano. Paralelamente, foi possível perceber a necessidade de superar pressupostos em torno das relações entre consumo e prática alimentar que permeiam grande parte dos trabalhos do campo da nutrição no Brasil. Nesse sentido, a ideia da adesão à "dieta ocidental" que tem servido de argumento explicativo para a frequência da obesidade na atualidade ${ }^{27,28}$ não parece explicar a prevalência do agravo entre as mulheres da Rocinha. As mulheres entrevistadas revelaram realizar uma dieta monótona, muito próxima à do roçado de subsistência composta basicamente 
por cereais, gorduras e açúcares. Assim, a adoção ao modelo de "dieta ocidental" não consegue explicar a prevalência da obesidade no grupo. A dieta rica em açúcares e gorduras não parece relacionar-se à incorporação de um modelo de alimentação "ocidental" ou "moderno", mas a aspectos culturais mais contraditórios e ambivalentes.

Assim, a alimentação das mulheres da Rocinha tende a ser rica em grãos, farináceos, tubérculos, açúcares e gorduras, o que demonstra a valorização dos alimentos tradicionais da cultura nordestina e da própria cultura alimentar brasileira. O típico "arroz com feijão", por exemplo, foi considerado pelas mulheres como a comida básica e indispensável, aquela que não pode faltar no dia a dia. Símbolo da cultura alimentar brasileira, o arroz com feijão exprime, como discutiu DaMatta ${ }^{29}$, a sociedade brasileira relacional, capaz de combinar o sólido com o líquido, o negro com o branco, gerando uma síntese, que integra o estilo brasileiro de comer. Dessa forma, sinalizamos a necessidade de resgatar a abordagem multidimensional para o estudo dos agravos nutricionais no país. Os exames que propõem a articulação das dimensões do corpo, do trabalho, da cultura, da condição de classe e saúde devem ser incorporados às temáticas atuais. Tal proposta implica superar quadros conceituais restritos e a construção de novas agendas de investigação. Nessa direção, uma nova perspectiva se anuncia para os estudos da área da nutrição e das ciências sociais em saúde.

\section{Colaboradores}

VA Ferreira foi responsável pela elaboração, redação e revisão do artigo; R Magalhães participou da orientação da pesquisa, da elaboração e revisão do artigo. 


\section{Referências}

1. Cândido A. Os parceiros do Rio Bonito: estudo sobre o caipira paulista e a transformação dos meios de vida. 9a ed. São Paulo: Duas Cidades, Editora 34; 2001.

2. Woortman K. Hábitos e ideologias alimentares em grupos de baixa renda [relatório final de pesquisa]. Brasília: Universidade de Brasília; 1978. (mimeo).

3. Velho OG. Hábitos alimentares em camadas de baixa renda [relatório do grupo de pesquisa]. Rio de Janeiro: Museu Nacional, Universidade Federal do Rio de Janeiro; 1977.

4. Loyola MA. Médicos e curandeiros: conflito social e saúde. Rio de Janeiro: Difel; 1984.

5. Duarte LFD. Vida nervosa nas classes trabalhadoras. Rio de Janeiro: Jorge Zahar, CNPq; 1986.

6. Rial CSM. Fast-foods: a nostalgia de uma estrutura perdida. Horizontes antropológicos 1996; 2(4):94-103.

7. Garcia RWD. Representações sociais da alimentação e saúde e suas repercussões no comportamento alimentar. Physis 1997; 13(3):455-476.

8. Lifschitz J. Alimentação e cultura: em torno do natural. Physis 1997; 7(2):69-83.

9. Silva DO. O fiel da balança na história do corpo obeso em mulheres de baixa renda [dissertação]. Rio de Janeiro: Escola Nacional de Saúde Pública Sergio Arouca, Fundação Oswaldo Cruz; 1997.

10. Rotemberg S. Práticas alimentares e o cuidado da saúde da criança de baixo peso. [dissertação]. Rio de Janeiro: Instituto Fernandes Figueira, Fundação Oswaldo Cruz; 1999.

11. Tonial SR. Desnutrição e obesidade: faces da desigualdade social no acesso aos alimentos e nas representações do corpo [tese]. Rio de Janeiro: Escola Nacional de Saúde Publica Sergio Arouca, Fundação Oswaldo Cruz; 2001.

12. Ferreira VA. Obesidade \& pobreza: o aparente paradoxo [dissertação]. Rio de Janeiro: Escola Nacional de Saúde Pública Sergio Arouca, Fundação Oswaldo Cruz; 2003.

13. Mendonça CP. Práticas alimentares e de atividade física de mulheres obesas atendidas em unidades de saúde pública do município de Niterói: trajetórias e narrativa [tese]. Rio de Janeiro: Escola Nacional de Saúde Publica Sergio Arouca, Fundação Oswaldo Cruz; 2005.

14. Canesqui AM. Antropologia e alimentação. Rev Saude Publica 1988; 22(3):207-216.

15. Canesqui AM. Comentários sobre os estudos antropológicos da alimentação. In: Canesqui AM, Garcia RWD, organizadoras. Antropologia e nutrição: um diálogo possível. Rio de Janeiro: Editora Fiocruz; 2005. p. 23-47.
16. Demo P. Introdução à metodologia da ciência. $2^{\text {a }}$ ed. São Paulo: Atlas; 1987.

17. Minayo MCS. Pesquisa social: teoria, método e criatividade. 9a ed. Petrópolis: Vozes; 1998.

18. Triviños ANS. Introdução à pesquisa em ciências sociais: a pesquisa qualitativa em educação. São Paulo: Atlas; 1987.

19. Bardin L. Análise de conteúdo. Lisboa: Edições 70; 1979.

20. Woortmann K. A família das mulheres. Brasília: Tempo Brasileiro, Tempo Universitário; 1987. (Coleção Biblioteca).

21. Woortmann K. Casa e família operária: anuário antropológico/80. Fortaleza: Edições Universidade Federal do Ceará, Tempo Brasileiro; 1982.

22. Canesqui AM. Mudanças e permanências da prática alimentar de famílias trabalhadoras. In: Canesqui AM, Garcia RWD, organizadoras. Antropologia e nutrição: um diálogo possível. Rio de Janeiro: Editora Fiocruz; 2005. p.167-210.

23. Canesqui AM. Comida de pobre, comida de rico: um estudo sobre alimentação num bairro popular [tese]. Campinas: Departamento de Medicina Preventiva e Social, Universidade Estadual de Campinas; 1976.

24. Zaluar A. A máquina e a revolta: as organizações populares e o significado da pobreza. 2a ed. São Paulo: Brasiliense; 1985

25. DaMatta R. Sobre o simbolismo da comida no Brasil. Correio da Unesco 1987; 7:22-24.

26. Freitas MCS. Educação nutricional: aspectos socioculturais. Revista de Nutrição 1997; 10(1):45-49.

27. Monteiro CA, Mondini L. Mudanças no padrão de alimentação. In: Monteiro CA, organizador. Velhos e novos males de saúde no Brasil: a evolução do país e de suas doenças. São Paulo: Hucitec, Nupes/USP; 1995. p.79-89.

28. Popkin BM. Nutritional patterns and transitions: population and development. Nutrition Review 1993; 19(1):138-157.

29. DaMatta R. O que faz o brasil, Brasil? Rio de Janeiro: Rocco; 1986.

Artigo apresentado em 22/12/2007

Aprovado em 06/06/2008

Versão final apresentada em 18/11/2008 